\title{
Psico-pediatria: a Importância do Brincar na Elaboração do Sofrimento da Criança Hospitalizada
}

\author{
Psycho-pediatrics: The Importance of Play in Elaborating the Suffering of Hospitalized Children
}

Raabe Francisca de Moura Duca Santos ${ }^{\dagger}$, Fátima Niemeyer da Rocha

Como citar esse artigo. SANTOS, R.F.M.D; DA ROCHA, F.N. Psicopediatria: a Importância do Brincar na Elaboração do Sofrimento da Criança Hospitalizada. Revista Mosaico, v.11, n.1, p. 93-98, 2021

\begin{abstract}
Resumo
O brincar é um direito essencial para a saúde emocional da criança, sendo a forma da criança se apresentar no mundo. No enfrentamento do adoecimento o brinquedo se apresenta como um recurso psíquico para minimizar os efeitos de uma hospitalização de longo prazo. Este artigo visa discutir a importância do brincar e da ludicidade na elaboração psíquica de crianças hospitalizadas, no âmbito dainternação pediátrica. Uma revisão da literatura especializada no assunto serviu de base para uma reflexão sobre a importância e o papel do lúdico no período de internação infantil. Este recurso contribui para o desenvolvimento infantil, minimizando os impactos exercidos pela situação de internação hospitalar, proporcionando bem-estar tanto físico, quanto psíquico, durante o período de internação, contribuindo com a equipe multidisciplinar para uma melhor qualidade de vidada criança hospitalizada.

Palavras-chave: Brincar/Ludicidade; Hospitalização;Elaboração do Sofrimento; Criança Hospitalizada.
\end{abstract}

\section{Introdução}

Uma criança ao ser internada passa por grandes alterações em sua vida social, familiar e pessoal, o que ocasiona mudanças em sua rotina, na qual, a cada dia, é submetida a tratamentos diversos e exames invasivos e dolorosos. Diante da ausência de suas costumeiras atividades diárias, de seus familiares mais chegados e de seus amigos, além de seus brinquedos prediletos, a criança sente-se angustiada, triste, insegura e com medo não somente pela possibilidade de abandono por parte do único familiar que a acompanha ao longo do período de internação, como também pelos procedimentos aos quais poderá ser submetida devido a hospitalização.

As crianças hospitalizadas, principalmente as mais jovens, não compreendem o que está acontecendo consigo, nem tampouco conseguem nomear em palavras seus sentimentos diante dessa nova situação. Assim, o brincar e atividade lúdica são inseridas no contexto hospitalar com o objetivo de fornecer à criança as condições necessárias para sua adaptação, reestabelecimento, compreensão e elaboração psíquica dos impactos da hospitalização.

Para Berto e Abrão (2009), o brincar apresenta-se como um recurso de enfrentamento da hospitalização, sendo um facilitador da realização de procedimentos médicos e da comunicação com a equipe hospitalar. Neste sentido, o brincar e o jogar são entendidos por Santa Rosa (1993) como formas de comunicação infantil, com as quais as crianças inventam o mundo e elaboram os impactos exercidos pelos outros.

O brincar é essencial para saúde física, mental e social da criança. Deste modo, o brincar proporciona à

\footnotetext{
Afiliação dos autores:

${ }^{\dagger}$ Psicóloga, Curso de Pós-Graduação Lato Sensu em Psicologia Hospitalar e da Saúde, Universidade de Vassouras, Vassouras, RJ, Brasil

* Doutora em Psicologia, Professora Titular, Curso de Psicologia, Universidade de Vassouras, Vassouras, RJ, Brasil
}

* Email de correspondencia: fatimaniemeyer@hotmail.com 
criança hospitalizada os meios para desenvolver novos repertórios de enfrentamento da doença, além de recursos de elaboração psíquica de angústias, medos tristezas e incertezas decorrentes da hospitalização infantil.

Nesta perspectiva, o presente artigo teve por finalidade discutir sobre a importância do brincar e do lúdico durante a hospitalização de crianças em psicopediatria. Buscou refletir sobre estes recursos serem considerados como meios de comunicação infantil, isto é, uma das formas pelas quais a criança interage com o mundo, sendo um importante recurso para a elaboração psíquica dos sofrimentos provenientes da hospitalização infantil. Para tanto, utilizou-se como metodologia uma revisão de literatura especializada,em livros e artigos científicos sobre o tema, levantados em bases de dados de publicações nacionais.

\section{O brincar e sua importância para o desenvolvimento infantil}

A infância é um período marcado por grandes transformações e mudanças físicas, psíquicas e sociais em que a criança, através do brincar, interage com o mundo que a cerca. A atividade lúdica e as brincadeiras sempre estiveram presentes na vida do indivíduo, desde a sua mais profunda ancestralidade, podendo ser consideradas importantes mecanismos de socialização; de acordo com Miranda (2001, p. 28), "do nascimento até a morte convivemos com elementos lúdicos". Além disso, desde os primórdios o ser humano buscou, através dos jogos, o autoconhecimento, sendo possível compreender a atividade lúdica como essencial para o crescimento e que, através dela, ocorrem experiências inteligentes e reflexivas para o desenvolvimento humano.

Há uma extensa linha de pensamento que, ainda, nos acrescenta o brincar como espaço de criação cultural. Winnicott (1975), por exemplo, traz o pensamento de que o espaço lúdico permite ao sujeito novo ou velho a liberdade de criação para com a cultura: "se brincar é essencial é porque brincando o paciente se mostra criativo".

$\mathrm{O}$ brinquedo favorece atividades geradoras de desenvolvimento emocional e social, de acordo com Cunha (1997), pois em qualquer momento, quando uma criança lança mão de um brinquedo, esse comportamento é um convite a novas aprendizagens, a interação social com outras crianças e a interiorização de crenças e valores. $\mathrm{O}$ ato de brincar é muito mais do que uma forma de passar o tempo para a criança; é sim sua principal forma de expressão, tanto verbal quanto não verbal, e sua forma de interação com o meio em que está inserida.

Santa Rosa (1993) pontua que brincar e jogar são as formas básicas da comunicação infantil, com as quais as crianças inventam o mundo e elaboram os impactos exercidos pelos outros. Esta afirmativa nos permite refletir que o brincar também tem sua importância no desenvolvimento mental da criança; através do brincar a criança projeta no brinquedo seus medos, angústias, frustações, dores e dificuldades, sendo importante instrumento para elaboração psíquica da criança.

O brincar oferece uma maneira de entrar no universo infantil, pois através das brincadeiras a criança acelera seu desenvolvimento. Por meio dessa atividade ela aprende a fazer, a conviver e, sobretudo, a ser, além de instigar sua curiosidade e autonomia, proporcionando, assim, o desenvolvimento da linguagem, da concentração e da atenção.

A teoria do brincar, desenvolvida por Winnicott (1975), parte do pressuposto de que a brincadeira é primária e não é um produto da sublimação dos instintos. É a forma básica da criança viver, é universal e própria da saúde, que facilita o crescimento e conduz a relacionamentos grupais, podendo ser vista sempre como experiência criadora.

Além disso, discorrer sobre a importância do brincar no desenvolvimento infantil exige esclarecer alguns conceitos relativos ao tema. $\mathrm{O}$ termo brincar, oriundo do latim ludere, significa laço, união; em português o vocábulo possui a especificidade de significarvínculo, que palavras correspondentes em outras línguas não apresentam (SANTA ROSA,1993). O brincar é uma forma de comportamento da infância que compõe a noção de jogo, e é também o ato de se divertir de modo geral, gracejar, zombar.

A brincadeira é fundamental no desenvolvimento cognitivo, afetivo e social da criança. Através do contato físico e social agrega conhecimento e ajuda a criança na compreensão da realidade que a cerca. Ao brincar ela cria relações sociais e vínculos e seus aspectos psicológicos vão sendo estimulados; portanto, é possível acrescentar que o brincar auxilia também no processo de aprendizagem e na elaboração psíquica de angústias e medos (SANTA ROSA,1993).

O brincar é de extrema importância para o desenvolvimento saudável da criança, através deste haverá a expressão e a elaboração dos seus conflitos, medos e angústias. Pela atividade lúdica é que a psicoterapia se efetua, favorecendo o acesso ao mundo simbólico da criança. Dessa forma, o brincar tem função importante para o desenvolvimento psíquico da criança, funcionando como defesa contra a ansiedade, e servindo como descarga emocional (SILVA, 2008).

Compreende-se, portanto, que o brincar auxilia no desenvolvimento integral da criança e favorece a elaboração psíquica de eventos difíceis de sua vivência, além dos possíveis impactos oriundos de relacionamentos com os outros, que podem ser intoleráveis para ela (SANTA ROSA,1993). 


\section{A importância da atividade lúdica no processo de hospitalização infantil}

Quando uma criança é diagnosticada com uma patologia e, naquele momento, necessita de hospitalização, pode ser tomada por um sentimento de insegurança e o medo se instala no seio familiar. Durante este processo são necessários cuidados e atenção especiais a esta criança que, fora de sua rotina familiar e social, é atravessada por sentimentos de abandono, insegurança, medo e revolta (FROTA, 2010).

Durante a internação, as crianças precisam receber os tratamentos médico e psicológico de acordo com sua faixa etária e sua condição clínica. Nesse cenário, um instrumento que pode ser inserido dentro da rotina hospitalar é o brincar, considerado um recurso que auxiliará e contribuirá para o desenvolvimento dessa criança e no enfrentamento do tratamento no período de internação (SILVA, 2008).

O brincar, no hospital, pode ser oferecido como um recurso terapêutico tanto com objetivos definidos, como melhorar o modo como a criança responde frente a patologia, quanto algo livre, sem objetivos concretos, apenas como um fator de acolhimento.A forma básica da criança se apresentar ao mundo ganha outro sentido durante a internação. Assim, como instrumento terapêutico o brincar pode ser importante para a construção da subjetividade da criança enferma, ao proporcionar uma oportunidade de melhor expressão de seus sentimentos, pensamentos e angústias relativos à doença, como também ao proporcionar à criança poder diminuir o sofrimento imposto pela hospitalização.

Soares e Zamberlan (2001) apontam para alguns problemas decorrentes da hospitalização infantil, como o descuido para com os aspectos psicológicos, pedagógicos e sociológicos envolvidos neste processo. Isto pode variar de acordo com a idade, com as experiências anteriores de hospitalização, com asvariáveis individuais e com os recursos de enfrentamento de cada criança e família.

A humanização hospitalar também se torna uma estratégia poderosa, pois as fantasias da criança adoecida, os seus medos e as suas angústias são tratados com todo o respeito necessário ao estado de sofrimento em que se encontra. Winnicott (1975) argumenta que quando a criança é bem atendida o retorno a saúde é acelerado.

O trabalho com ludoterapia no contexto hospitalar pode ser realizado mediante diversas técnicas e recursos: desenho, pintura, fantoche, mímica, literatura e até mesmo teatro (LIMA et al., 1985). As brincadeiras proporcionam relaxamento, ajudam a criança a se sentir segura, diminui o medo, o estresse e a angústia e estimula os vínculos da criança tanto com a família como com a equipe multidisciplinar, facilitando também a sua adesão ao tratamento.
A rotina de uma criança não hospitalizada é marcada durante anos por horários para comer, brincar, se vestir e ir à escola, entre outras atividades. Entretanto, quando esta adoece e precisa ser hospitalizada essa estrutura familiar de horários rotineiros é quebrada.

Na maior parte do tempo a criança será restrita ao leito, submetida a passividade e a procedimentos invasivos e dolorosos, cercada de pessoas que ela não conhece, com horários institucionais para banho e refeições, distante de familiares, amigos e brinquedos que gosta. Tal situação pode levar a criança, durante a hospitalização, segundo Sadala e Antônio (1995), por exemplo, a recusar os alimentos sólidos, regredir a verbalização e diminuir o controle dos esfíncteres, além de outras reações emocionais importantes, como choro excessivo e a expressão de medos e angústias.

Nesse sentido, apesar do grande avanço quanto a atenção em Psico-pediatria, é necessário diminuir os estressores da hospitalização infantil com a oferta de atividades lúdicas à criança hospitalizada, a fim de evitar consequências negativas da hospitalização de longo prazo, principalmente, e favorecer elaborações psíquicas de eventos traumáticos.

No sentido de que o brincar é próprio da criança e essencial para sua saúde física e mental, segundo Winnicott (1975,p.80), “é no brincare somente no brincar que o indivíduo, criança ou adulto pode ser criativo e utiliza sua personalidade integral. E é somente sendo criativo que o indivíduo descobre o seu self" E conforme o Estatuto da Criança e do Adolescente (BRASIL, 1990) brincar é direito que deve ser assegurado para criança de qualquer idade.

A brincadeira favorece a criação de um contexto de diversão e a expressão de sentimentos, emoções e culpas acerca do que a criança está vivenciando naquele contexto. Para Ângelo e Vieira (2010), pela simbolização lúdica a criança transfere, no ato de brincar, suas fantasias, medos e ansiedades para os objetos, onde a brincadeira dá um contorno ao impacto provocado pelo outro e também diminui o sentimento de impotência familiar frente ao adoecimento e a sua hospitalização.

A internação hospitalar infantil pode ser potencialmente traumática para a criança e sua família, pois traz alterações em sua rotina, para a dinâmica familiar, provoca o distanciamento do seu contexto habitual. Além disso, o hospital pode ser entendido como um ambiente onde a criança encontra-se numa situação de fragilidade, sendo necessário meios e recursos para que a mesma elabore esses sentimentos e fantasias provenientes do adoecimento e da hospitalização. Entretanto, a condição de hospitalização desempenha um papel importante na manutenção da saúde de crianças enfermas, embora nesta situação possam surgir condições que dificultem a adesão a esse contexto novo (LAURENT;RUMEU, 1990).

Gaetan (1997) discute que tanto a hospitalização 
como a doença em si podem trazer estresse para a criança, que pode entrar num nível significativo de sofrimento emocional e físico, em decorrência da hospitalização. Para Domingos (1993) essa situação pode criar ameaças reais ou imaginárias que podem ser expressas através do medo, do choro excessivo, da agressividade, da dependência, da ansiedade, da depressão, dos distúrbios do sono, da evitação dos procedimentos e de outras respostas, como também da falta de apetite e de regressãoa um estágio de desenvolvimento anterior.

Para Berto e Abrão (2009), neste sentido, o brincar apresenta-se como um recurso de enfrentamento da hospitalização e também como um facilitador de procedimentos e da comunicação com a equipe hospitalar. Ângelo e Vieira (2010), por sua vez, definem que, "entendido o brincar como função básica da criança, os atendimentos às crianças hospitalizadas pelo uso do lúdico apresentam-se como alternativa que permite acesso ao mundo simbólico infantil.

De acordo com o Ministério da Saúde (BRASIL, 2005), a Lei 11.104 de 2005 define que os hospitais que oferecem o atendimento pediátrico devem contar com um espaço de brinquedoteca. Para Ângelo e Vieira (2010), é neste espaço que as crianças vão compartilhar alegrias e tristezas e diminuir os efeitos negativos da hospitalização. E Goulart e Moraes (2000) defendem que este espaço lúdico no hospital possibilita atividades para atenuar as sequelas emocionais e dar continuidade ao ritmo do desenvolvimento da criança.

No parecer de Ribeiro (1998), o brinquedo terapêutico no hospital é algo que proporciona a redução da ansiedade nas situações de dor e sofrimento. Permite à criança externalizar pelo brincar os seus medos, sentimentos e necessidades através de verbalizações das experiências difíceis de forma que alivie suas tensões. E Santos e Ferreira (2003) acrescentam que os jogos também podem contribuir para o desenvolvimento da criança durante a atividade lúdica, transformando angústia em prazer. Além disso, entendem que os jogos permitem a elaboração dos desejos e a expressão da agressividade, assim como a associação entre liberdade e limite.

\section{O brincar como instrumento de elaboração psíquica - a psico-pediatria}

No cenário da psico-pediatria surge, então, um ponto a ser problematizado: como o brincar e a atividade lúdica favorecem a elaboração psíquica do sofrimento da criança hospitalizada?; uma vez que a forma de operação psicanalítica trabalha a partir da palavra, fazendo com que muitos profissionais valorizem o significado linguístico, limitando a linguagem apenas às palavras.

Santa Rosa (1993) afirma que o brincar é um conceito perpassado pelo campo da linguagem que constitui a realidade psíquica. A partir disso, torna-se possível afirmar que,mesmo fazendo uso de um método que não opere exclusivamente a partir de associações verbais, é também possível fazer com que o mesmo não sofra desvios na regra básica que deve regê-lo.

O brincar é uma atividade na qual a criança utiliza sua imaginação e criatividade, criando e recriando situações do seu cotidiano ou ambiente que o cerca naquele momento. Durante o processo de hospitalização, ao ofertar à criança a possibilidade de desenvolver uma atividade lúdica, a equipe multidisciplinar tem a oportunidade de acesso a criança de forma integral.

Durante um longo processo de hospitalização, as crianças precisam receber um tratamento multidisciplinar de acordo com sua faixa etária e história clínica. E os profissionais de saúde, neste contexto, precisam compreender cada vez mais as demandas físicas e psíquicas que surgem ao longo desse processo.

Em Psico-pediatria é necessário que a equipe oferte à criança intervenções que reduzam o risco de agravamento da patologia clínica que ela apresenta. Portanto, ao inserir o brincar e a atividade lúdica neste contexto a equipe possibilita à criança externalizar no brinquedo as suas emoções, ansiedadese medos, melhorando assim a sua qualidade de vida e também de seus acompanhantes ao longo do processo de hospitalização. (MOTTA; ENUMO 2010).

Desta forma, o brincar e a atividade lúdica dentro do contexto pediátrico poderãoser utilizados para a melhoria do quadro clínico apresentado pela criança, de uma melhor compreensão dos procedimentos realizados com ela, do bem-estar físico e psicológico e, também, como um recurso de elaboração psíquica de conflitos traumatizantes que possam ocorrer (FREUD, 2001).

É importante ressaltar ainda, sobre a importância do brincar neste contexto, que a criança hospitalizada e os seus familiares passam por momentos de medo, angústia e agitação em um ambiente institucional marcado por dores, incertezas e a presença constante de pessoas estranhas a eles. E o brincar e a atividade lúdica favorecem o acesso a esta criança, através da elaboração psíquica, pelo brinquedo, de tudo o que é intolerável para a criança, numa situação na qual ela pode se sentir livre para externalizar os dados da sua realidade interna, isto é, seu sofrimento, angústias, medo e conflitos.

A criança que brinca é aquela que teve uma boa elaboração do espaço potencial com sua mãe, aprendeu a estar sozinha e elaborou a capacidade de criatividade, sendo, portanto, uma criança com mais recursos de enfrentamento de situações difíceis. Já a criança que não brinca ou o faz de maneira compulsiva e repetida pode estar sinalizando um sofrimento psíquico acompanhado de uma forte angústia (COSTA,2010), os quais devem ser alvo de acompanhamento psicológico. 
O brincar é uma atividade na qual a criança utiliza da imaginação e da criatividade, criando e recriando situações do seu cotidiano, como uma forma de diminuir a ansiedade e a angústia, e na elaboração de seus conflitos. No contexto hospitalar os conflitos psíquicos são gerados pela fantasiaem relação a realidade e, quanto mais for elaborado na brincadeira, maiores são as chances de haver uma reconfiguração do sofrimento psíquico.

No âmbito clínico, o brincar em Psico-pediatria é utilizado com um dos principais mecanismos de comunicação dacriança, onde a fala não é necessariamente verbal, mas, a partir dela, há uma maior possibilidade da equipe hospitalar ter acesso ao mundo simbólico da criança. O brincar, como linguagem, é importante porque permite trocas entre os sistemas inconsciente, pré-consciente e consciente a partir da articulação das imagens e gestos com significado linguístico, favorecendo o acesso à criança pela atividade lúdica.

O brincar,como citado anteriormente, tem uma função importante para o desenvolvimento psíquico da criança, uma vez que funciona como uma defesa contra a ansiedade, servindo de descarga emocional na qual é possibilitada a liberação de conflitos infantis. No processo lúdico tais conflitos se repetem, visto que a criança expressa simbolicamente sua fantasia e seus desejos inconscientes no contexto que a cerca.

Em função disso, o ato de brincar realiza uma função psíquica na criança: a construção da fantasia e a expressão das pulsões (SILVA, 2008), em que, independente do contexto, seja clínico ou hospitalar, no ato de brincar, ou seja, com acesso à atividade lúdica, a criança cria, recria e elabora eventos de sua vivência, assim como os impactos exercidos pelos outros em sua vida, por vezes de caráter intolerável para ela.

\section{Consideraçoes Finais}

$\mathrm{O}$ artigo objetivou discutir a respeito da importância do brincar para a criança hospitalizada. Buscou sinalizar o papel das atividades lúdicas para o desenvolvimento da criança, como um recurso que favorece expressão de sentimentos, emoções, angústias, medos e ansiedades, no processo de internação pediátrica. Observou-se que, quando o brinquedo é oportunizado à criança, ela projeta nele os dados de sua realidade e expressa pelo brincar o que vivencia, elaborando o sofrimento causado pelo adoecimento e pela hospitalização.

Ao ofertar atividades lúdicas no contexto hospitalar infantil, estes se tornam importantes recursos na construção subjetiva da criança, influenciando seu desenvolvimento, tanto físico, quanto emocional e social, assim como auxilia na reconfiguração do que, a princípio, tem somente significado de sofrimento e dor, na possibilidade, pelo brincar, de elaboração e ressignificação da experiência vivida pela criança hospitalizada.

Através da ludicidade a criança se torna capaz de estabelecer relações positivas com o ambiente do hospital e entre o fazer e o sentir, que representa uma forma de enfrentamento da doença, ampliando e melhorando o seu prognóstico e a qualidade da assistência no processo de hospitalização pediátrica.

\section{Referênciais}

ÂNGELO, T.S.;VIEIRA, M. R. R.Brinquedoteca hospitalar: da teoria à prática. Revista Arquivos de Ciência da Saúde,v. 17,n. 2, p. 84-90,2010.

BERTO, C. E. O.;ABRÃO, J. L.F. A importância do brincar no contexto hospitalar: percepção e compreensão de equipe de enfermagem: Revista de Psicologia da UNESP, v. 8, n. 2, p. 154-157, 2009.

BRASIL. Ministério da Saúde. Estatuto da Criança e do adolescente. Lei N ${ }^{\circ}$ 8.069, de 13 de Julho de 1990.Brasília: 1990.

BRASIL. Lei $\mathrm{n}^{\circ} 11.104$, de 21 de março de 2005. Dispõe sobre a obrigatoriedade de instalação de brinquedotecas nas unidades de saúde que ofereçam atendimento pediátrico em regime de internação. Brasília: Diário Oficial da República Federativa do Brasil, 2005. Disponível em: http://www. planalto.gov.br/ccivil 03/ Ato2004-2006/2005/Lei/L11104.htm. Acesso em: 1 mar. 2020.

COSTA, T.Psicanálise com crianças. Rio de janeiro: Zahar, 2010.

CUNHA, S. L. Brincando se aprende. São Paulo: EDUSP,1997.

DOMINGOS, N.A.M.Preparo para cirurgia. Testes de programas psicológicos na redução de ansiedade de mães e crianças. Dissertação de Mestrado,PUC - Campinas, 1993.

FREUD, S. Três ensaios sobre a teoria da sexualidade. Rio de Janeiro: Imago, 2001.

FROTA, M. A. O lúdico como instrumento facilitador na humanização do cuidado de crianças hospitalizadas. Cogitare Enfermagem,v. 12, n. 1, p. 69$75,2010$.

GAETAN, R.M.C. O estresse da criança. Seminário daPsicologia da Saúde. São José do rio preto: UNORP, 1997

GOULART, A.M.P.;MORAIS, S.P.G. O brincar como ação mediadora no trabalho desenvolvido com crianças hospitalizadas.In:SANTOS, S. M. P. (org.). 2. ed. Petrópolis: Vozes, 2000.

LAURENT, A. P.; RUMEU, O. L. Programas para Ia preparación a Ia hospitalización infantil. In: J.M. Buceta \& A. M. Bueno, Modificación de conductaysalud: Perspectivas actualesen Ia aplicación de tratamientos de psicologia. Eudema, 1990

LIMA, A. M.; KAKEHASHI, T. Y.; BARBOSA, V. L. A criança e a família frente a hospitalização. Enfermagem Moderna, v. 3, n.3, p. 45-52, 1985.

MIRANDA, S. Do fascínio do jogo a alegria do apreender nas séries iniciais. São Paulo: Papirus,2001.

MOTTA, A.B.;ENUMO, S. R. F. Intervenção psicológica lúdica para enfrentamento da hospitalização em crianças com câncer. Psicologia: Teoria e Pesquisa, v. 26, n. 3, p. 445-454, 2010.

RIBEIRO, C.A.O brinquedo terapêutico na assistência à criança hospitalizada Revista da Escola de Enfermagem da USP, v. 32, p. 73-79, 1998.

SANTA ROSA, E. Quando brincar é dizer: a experiência psicanalítica na infância. Rio de Janeiro: Relume-Dumara,1993.

SANTOS, M. L.O.; FERREIRA, I. C. S. O lúdico como recurso alternativo na terapêutica hospitalar. Revista da Rede de Enfermagem do Nordeste, v. 4 , p. $38-45,2003$ 
SADALA, M. L. A.; ANTONIO, A. L. O. Interagindo com a criança hospitalizada: utilização de técnicas e medidas terapêuticas. Rev. LatinoAm. Enfermagem, Ribeirão Preto, v. 3, n. 2, p. 93-106, July 1995.

SILVA, S.M.Benefícios das atividades lúdicas na recuperação das crianças com câncer. Boletim Acadêmico: Revista de Psicologia, v. 28, n. 2, p. 211$221,2008$.

SOARES, M.R. Z.;ZAMBERLAN,M. A. T.A inclusão do brincar na hospitalização infantil. Estudos de Psicologia,v. 18, n. 2, 64-69. 2001.

WINNICOTT, D.W. O brincar e a realidade. Rio de Janeiro: Imago, 1975. 